\title{
BREVE BALANCE Y PERSPECTIVAS DE LA INDUSTRIA MAQUILADORA DE EXPORTACIÓN*
}

\author{
Por \\ Jesús Tamayo**
}

\section{RESUMEN}

En este trabajo se muestra un panorama general sobre la industria maquiladora ( $(\mathrm{M})$ en donde se analiza el desarrollo de esta actividad, desde sus orígenes hasta la fecha, destacando sus nexos con el proceso de urbanización de la frontera norte de México y los retos que enfrenta en ambos países.

\begin{abstract}
This work shows a general view of the maquiladora industry and analyzes the development of this activity, from its origins to this date, stressing its links with the process of urbanization of the North border of Mexico and the challenges that faces in both countries.
\end{abstract}

\section{ANTECEDENTES}

\section{Los factores externos}

Es conocido que el proceso de industrialización de nuestro extremo norte comenzó a mediados de los años sesenta. Aunque oficialmente se aduce que tal proceso fue resultado de una estrategia gubernamental mexicana para enfrentar el desempleo fronterizo ocasionado por la caída de la producción algodonera y la terminación del programa bracero, nos parece que nuestra industrialización fronteriza responde más a dos factores externos: a) los avances tecnológicos de los países industrializados en los

\footnotetext{
- Una versión preliminar de este documento ha sido presentada en da Academia de Problemas Económicos y Sociales de México de la Universidad Antonio Narro, en Saltillo, Coahuila, en marzo de 1992, y en el Foro sobre la Problemática de las Ciudades Fronterizas, organizado por la Comisión de Asentamientos Humanos y Obras Públicas de la Cámara de Diputados (LX Legislatura), en Tijuana, B.C. en mayo de 1992.

** Investigador del Centro de Investigación y Docencia Económica.
} 
afios sesenta, ${ }^{1}$ que hicieron posible la segmentación de algunos procesos productivos en ciertas industrias, ${ }^{2}$ y b) el desarrollo de los sistemas de transporte y comunicaciones que hizo posible, por ejemplo, la transmisión de órdenes de trabajo y el envío de insumos y de productos semiterminados entre plantas distantes a un costo relativamente bajo. Ello habría cristalizado en el surgimiento de "zonas francas" o "plataformas de exportación" en algunos países de bajo nivel de desarrollo ${ }^{3}$ y en la adecuación de las regulaciones aduanales de los países industrializados de modo que insumos y productos semiterminados pudiesen exportarse para ser ensamblados o terminados en aquellas plataformas y regresar después al país de origen para ser terminados, consumidos o reexportados a un tercer país. ${ }^{4}$ En México, las viejas "zonas y perímetros libres" del extremo norte se transformaron fácilmente en plataformas de exportación. ${ }^{5}$

\section{Las primeras maquiladoras}

La primera planta maquiladora se estableció en Nuevo Laredo en 1965. Cinco años después, en 1970, las maquiladoras empleaban ya a 30 mil trabajadores a lo largo de la frontera. En 1975, diez años después de creadas, los puestos en el sector habían crecido a 60 mil. $^{6}$

La industria maquiladora alteró pronto las economías fronterizas basadas tradicionalmente en los servicios aduanales y en la venta de servicios personales a las poblaciones estadounidenses vecinas (la actividad agrícola sólo era relevante en Mexicali, Juárez y en el bajo Río Bravo).

1 Nos referimos aquí al desarrollo de la tecnología de los llamados microconductores y a su correlato: al proceso de miniaturización de partes, componentes y del equipo eléctrico y electrónico. Ello sería aprovechado pronto por el sector productor de electrodomésticos y por el de partes eléctricas automotrices.

En la industria electrónica, por ejemplo, el ensamble de partes, componentes y equipo, fase "intensiva en mano de obra", se convirtió en una etapa económicamente costosa si se llevaba a cabo en algún país desarrollado, pero que podría ser trasladada a alguna "plataforma de exportación" donde el ahorro en salarios fuese mayor que el costo de transportar los productos semiterminados a tal lugar. La baja relación peso/valor de partes y componentes ęlectrónicos hizo más atractiva la segmentación de las fases de ensamble.

Por ejemplo, las "zonas francas" de Seúl de Inchon, Corea, fueron creadas en 1960; la de Kaoshiung, Taiwan (Formosa), data de 1965. De los mismos años datan Shanon en Irlanda, y las "zonas francas" de Singapur, Hong Kong, Filipinas, India y México.

De aquí la popularidad de las fracciones arancelarias estadounidenses 806.30 y 807 , que regulan aún la exportación temporal de insumos y productos semiterminados.

La primera legislación maquiladora en nuestra país surgió, a mediados de los sesenta, de la reglamentación del párrafo 3ro. del Artículo 321 del Código Aduanero, el cual regulaba las importaciones temporales.

6 Este crecimiento supera al de las "zonas francas" de Seúl e Inchon que, quince años después de creadas, contaban con 80 mil trabajadores, o al de Kaoshiung que diez años después de creada contaba con 41 mil trabajadores (Cfr. Hyun Sook, 1992:177-181). 
A mediados de los años setenta las autoridades mexicanas se interesaron por el fenómeno maquilador. La industria maquiladora representaba, en 1975 , el $4 \%$ del total del empleo y de los salarios manufactureros, y desde entonces se advertía su carácter altamente dinámico.

\section{Importancia en los años setenta}

La maquiladora era en los sesenta de gran importancia en la frontera norte de México. En 1975 se convierte en la industria fronteriza. Si bien ese año las maquiladoras representaban apenas el $10 \%$ de las plantas manufactureras en aquellas regiones, contribuían ya con el $72 \%$ y el $70 \%$ de los trabajadores y de los salarios industrial manufactureros, ${ }^{7}$ y su importancia crecía a nivel subregional. Según las estadísticas del sector, ese mismo año, $25 \%$ del empleo maquilador se concentraba en cinco municipios del extremo noroeste de la frontera, de Ensenada a San Luis Río Colorado; otro $32 \%$ de la ocupación se ubicaba en Ciudad Juárez; y otro $20 \%$ se ubicaba en el noreste, de Nuevo Laredo a Matamoros. El resto se distribuía entre media docena de localidades fronterizas. El empleo maquilador representaba el $49 \%$ del empleo manufacturero en la zona noroeste, $86 \%$ en Ciudad Juárez y más del $40 \%$ en la zona noreste. Fue por esos años que las autoridades mexicanas encargaron al Centro de Investigación y Docencia Económicas (CIDE) un estudio del sector.

\section{La encuesta nacional de $1979^{8}$}

En 1979, el CIDE llevó a cabo una encuesta de la que se obtuvieron algunas características sobresalientes de la industria maquiladora mexicana (IM) de esos años; aquellas eran las siguientes.

- La IM era una industria altamente especializada o, dicho de otro modo, sectorialmente concentrada. En 1979, el 60\% de las plantas y el $73 \%$

7 Esto significa que antecedio a la maquiladora una industria no-maquiladora regional que si bien registraba entonces el $90 \%$ de las plantas, sólo empleaba al $28 \%$ de los trabajadores gue recibian el $30 \%$ de los salarios del sector manufacturero.

La "Encuesta nacional de plantas maquiladoras" (ENPM), fue realizada por el cme en septiembre de 1979: cubrí un total de 305 plantas y 65,728 trabajadores de un universo estimado de 489 plantas registradas como maquiladoras de exportación y cuya ocupación se geportaba de 86,715 trabajadores.

Esta síntesis de la información de la ENPM fue presentada al Workshop on the Border Industrialization Program, University of Califomia, Berkeley, enero 1982. Un reporte pormenorizado de la encuesta del CDE ha quedado en Zonas Fronterizas (México- Estados Unidos), CIDE, México 1983. 
del empleo maquilador se ubicaban en solamente tres ramas o subsectores, cl del vestido (costura), cl cléctrico y el electrónico.

- La IM era una industria o sector "técnicamente concentrado". En 1979. las plantas mayores, aquéllas que empleaban cada una a más de 500 trabajadores (y que eran el 10\% del total de las plantas), utilizaban el $48 \%$ de la fuerza laboral del sector; en el otro extremo, las plantas menores, aquéllas que empleaban menos de 50 trabajadores (y que eran el 34\% del total de las plantas), ocupaban sólo el $4 \%$ de la fuerza laboral. Ese afio, sólo 36 plantas concentraban el $50 \%$ de la ocupación maquiladora.

- La IM era una industria o sector controlado por el capital extranjero, tanto en términos de su capital social como a través de los flujos de sus insumos y sus productos. En cuanto a la participación del capital extranjero, $53 \%$ de las maquiladoras eran propiedad de extranjeros en un $100 \%$, y en otro $9 \%$ de las plantas el capital extranjero era mayoritario. Así, más del $60 \%$ de las plantas maquiladoras estaban entonces directamente controladas por el capital extranjero. ${ }^{10}$ En términos de empleo, 73\% de los trabajadores estaban empleados en plantas $100 \%$ propiedad de extranjeros, $y$ un $12 \%$ adicional estaban empleados en plantas con capital mayoritariamente extranjero.

En ese tiempo, la IM estaba controlada a través de los flujos de sus insumos y de sus productos. En 1978 (el affo de la encuesta), el 87\% de las plantas recibían todos sus insumos de Estados Unidos y el $85 \%$ de ellas exportaban toda su producción al mismo país.

Las plantas maquiladoras estaban frecuentemente controladas a través de sus activos fijos. El $46 \%$ de las plantas maquiladoras nacionales informaron que usaban maquinaria y equipo propiedad del contratista. Este por ciento alcanzabael $87 \%$ en el sector eléctrico y $77 \%$ en el electrónico.

\section{La crítica de los años ochenta}

A principios de los años ochenta, la maquiladora fronteriza cra objeto de cuestionamientos económicos, sociales y políticos; entre los principales podemos señalar los siguientes: a) el carácter contradictorio del modelo maquilador fronterizo respecto del modelo de industrialización vigente en el resto del país. ${ }^{11}$ Tal contradicción se observaba en términos de la inversión extranjera directa que cada uno de estos modelos atraía (Fernández

${ }^{10}$ Los por cientos eran aún mayores en dos de los más imporantes sectores: $82 \%$ en el electrónico y $37 \%$ en el eléctrico. 
y Tamayo, 1986). Ello desarticulaba a la IM del aparato productivo nacional y le confería un carácter de enclave; ${ }^{12}$ b) asimismo se observaba a la IM altamente vulnerable al ciclo económico estadounidense; c) se ponía en duda su contribución a la captación de divisas dado el alto contenido de importaciones en el consumo fronterizo (era claro que el efecto multiplicador del ingreso maquilador se filtraba a las economías vecinas en las primeras rondas de gasto) (Fernández y Tamayo, 1983). Ni siquiera se aceptaba que la IM contribuía positivamente a la ocupación regional; d) $\mathrm{Si}$ la IM prefería la mano de obra femenina, extremadamente joven y sin experiencia laboral, era obvia su escasa contribución al abatimiento de la desocupación en la región; e) se le cuestionaba inclusive, su contribución en la capacitación de los trabajadores regionales.

Por otra parte, los argumentos a favor de la maquiladora provenían de quienes advertían la creciente internacionalización del capital y presentían que la maquiladora era la variedad local del fenómeno global llamado production sharing. ${ }^{13} \mathrm{Su}$ argumentación llega hasta nuestros días; no favorecer entonces la IM era poco menos que ir en sentido contrario a la modemización, cuando no a la hiștoria misma. ${ }^{14}$

Los gobiernos federales, estatales y municipales, sin dar muchas explicaciones, también favorecieron en los hechos a la IM. Contar con más maquiladoras en la frontera se convirtió en el objetivo extraoficial de los gobernantes fronterizos. Cualquier maquiladora era mejor que ninguna.

\section{Efectos de urbanización y de otro tipo}

No conocemos algún análisis que establezca relación estadística entre la maquiladora y el crecimiento demográfico regional, pero parece evidente que la maquiladora contribuyó significativamente en la urbanización reciente del norte de México. En las últimas décadas, las tasas de crecimiento de la población municipal y de la población de las principales ciudades del extremo norte se contaron entre las más altas del país.

\footnotetext{
11 Mientras el régimen interior era "sustitutivo de exportaciones" y restrictivo para con la inversión extranjera directa (IED), el régimen fronterizo era exportador y muy liberal con la IED, al extremo de favorecer la existencia regional de un régimen laboral excepcional.

12 Véase un análisis reciente acerca de la limitada integración de las maquiladoras a la economía mexicana y de sus pobres efectos secundarios en el resto de los sectores de la economía (Guajardo, 1992: 42-45).

${ }^{13}$ Es curioso que cien años antes se llamo "socialización de la producción" al fenómeno que un siglo más tarde sería redescubierto y rebautizado como production sharing o división internacional del trabajo.

${ }^{14}$ Desde la perspectiva opuesta, la IM era la expresión local de la "nueva división intemacional del trabajo", una fase superior del capitalismo.
} 
Las tasas de urbanización fronteriza fueron muy superiores a las tasas de crecimiento de la infraestructura de los municipios fronterizos, es decir, de la construcción de redes de abastecimiento de agua potable, de drenajes, de sistemas de tratamiento de aguas residuales. No se dedicó tiempo para planificar el crecimiento urbano o el industrial. Con excepción de Ciudad Juárez, los "parques industriales" (cuya sola existencia implicaba una primera idea de organización urbana) se conocieron en las localidades fronterizas hasta los primeros años de la década de los ochenta. $^{15}$

\section{Cambio de rumbo y nueva inversión}

No obstante la crítica y las primeras evidencias, la industria maquiladora siguió creciendo favorecida por un cierto sector empresarial y la simpatía de los gobiernos federales mexicano y estadounidense. La crisis de 1982 y la decisión política de reemplazar al proyecto económico nacional, "sustitutivo de importaciones", por un modelo promotor de exportaciones, silenció progresivamente todo tipo de críticas al esquema maquilador que entonces se convirtió en el modelo a seguir.

La política económica puesta en práctica a partir de la crisis de 1982 incluyó la drástica subvaluación del peso frente al dólar. Lo cierto es que, al margen del efecto devastador que en lo inmediato esta medida tuvo en la población fronteriza, en el mediano plazo alentó la llegada a la región de nueva inversión en el sector maquilador.

La nueva posición competitiva regional, derivada del bajo costo en dólares de la mano de obra fronteriza quizá contribuyó también a la llegada a la región de inversión asiática, principalmente japonesa, que pronto introdujo nuevas técnicas de organización para el trabajo. Evidentemente, el interés asiático era y es el mercado estadounidense. En los últimos años, grandes firmas asiáticas se establecieron en nuestro extremo norte. Hoy el sector maquilador tiene dos componentes: el estadounidense y el japonés. ${ }^{16}$

15 Hoy, a la distancia, podríamos apuntar a vuela pluma otros (casi evidentes) efectos de la implantación de la IM de exportación en nuestra frontera norte, es decir, de la transformación de las pequeñas economías fronterizas, agrícolas o de servicio, a economías ensambladoras (más o menos) industrial manufactureras. Los más importantes, nos parece, son los efectos sociales y los políticos. El más relevante de los primeros quizá sería la creciente sustitución de los patrones sociales tradicionales en aquellas regiones, por otros que podríamos calificar de externos. El más importante de los segundos sería, tal vez, la también creciente importancia sociopolítica, local y estatal, de empresarios y administradores maquiladores, quienes en los últimos años habrían desplazado a la clase política tradicional (surgida de, e integrada por ganaderos, agricultores y funcionarios aduanales). El análisis de tales efectos reta hoy a sociólogos y politólogos. 


\section{ALGUNOS EFECTOS DE LA LIBERALIZACIÓN DE LOS AÑOS OCHENTA}

La apertura económica y la alineación política mexicana con el bloque estadounidense - esbozada en 1982, iniciada en 1985 y declarada abiertamente en 1989- tiene una curiosa implicación regional fronteriza: al extender el régimen liberal al resto del país, hace desaparecer el tratamiento fiscal comercial de excepción en el que ha vivido la población y el comercio fronterizo desde hace sesenta años; también disuelve progresivamente ( 20 extiende?) las ventajas que gozaba en exclusiva la maquiladora fronteriza (excepcionalidad frente a la Ley de Inversiones Extranjeras y a la Ley Federal del Trabajo, por ejemplo). ${ }^{17}$ Esta relativa pérdida de los privilegios fronterizos hará o hace ya aparecer ventajas locacionales en el interior del pais; sobre todo en centros urbanos del norte como Monterrey y quizá Saltillo, cuya infraestructura física y sus antecedentes industrial manufactureros sugieren una mayor eficiencia local de obreros, técnicos y administradores.

\section{Internación de la IM}

Así, otra característica reciente de la IM es su incipiente "internación" o "internalización" (Quintanilla, 1991: 861-869). En las estadísticas del sector, el peso relativo de la maquiladora fronteriza frente a la no-fronteriza ha venido decreciendo, a este efecto numérico parece haber contribuido no sólo la localización real no-fronteriza de nuevas plantas ensambladoras sino también la nueva política de promoción de exportaciones que hizo posible que, desde mediados de la década pasada, industrias orientadas al mercado interno y con capacidad ociosa pudiesen, simultáneamente, maquilar para la exportación, acogiéndose al régimen respectivo.

\section{El perfil actual de la IM}

Las estadísticas oficiales del sector maquilador dejan ver que en 1989 tenía el perfil que se muestra en el siguiente cuadro:

${ }^{16}$ El reciente crecimiento fronterizo de las empresas asiáticas, principalmente japonesas, ha sido notable. A fines de 1990 ya se contaban 45 maquiladoras asiáticas ( 39 de ellas japonesas) en Tijuana y Mexicali, mientras que cinco anios atrás sólo había cinco (Cfr. Castillo y Ramírez, 1992: 33-41).

17 Hoy, el Consejo Nacional de la Industria Maquiladora de Exportación explora y negocia con el gobiemo nuevas ventajas para sus afiliados. Las autoridades de la SECOFI, por su parte, sc apresuran en serialar que "los acuerdos trinacionales para el sector maquilador en el TLC [,...] garantizan la consolidación de la tendencia expansiva mostrada por la industria en los años recientes" (Cfra "Se ajustará el decreto de la industria maquiladora". La Jornada, 16 de octubre de 1992). 
CUADRO 1. México y municipios fronterizos. Características de la industria maquiladora de exportación 1991.

\begin{tabular}{lrrr}
\hline & México & $\begin{array}{r}\text { Municipios } \\
\text { fronterizos }\end{array}$ & $\%$ \\
\hline Establecimientos & 1655 & 1329 & 80.3 \\
Trabajadores $\propto$ cupados & 429725 & 339918 & 79.1 \\
$\quad 349602$ & 275978 & 78.9 \\
$\quad$ Obreros & 214521 & 160413 & 74.8 \\
$\quad$ Mujeres & 3.812 & 3.151 & 82.7 \\
Sueldos y salarios* & 1.054 & .864 & 82.0 \\
$\quad$ Prestaciones & 23.550 & 20.155 & 85.6 \\
Insumos* & 23.177 & 19.951 & 86.1 \\
$\quad$ Importados & .372 & .204 & 54.8 \\
$\quad$ Nacionales & 7.499 & 5.924 & 79.0 \\
Valor agregado* & 1.248 & .970 & 77.7 \\
Utilidades imputadas* & & & \\
\hline
\end{tabular}

FUENTE: Estadística de la industria maquiladora de exportación 1979-1989. México, 1991. INEGI.

* Billones de pesos.

\section{Nuevos problemas alrededor de la IM}

En los años ochenta, la maquiladora, más o menos silenciosamente, se transformó en importadora temporal de substancias peligrosas, cuando no prohibidas, en Estados Unidos. En efecto, en esos años, nuevas empresas llegaron a México atraídas no sólo por los bajos salarios sino por la laxitud de las reglamentaciones ambientales.

Como es sabido, según la ley mexicana, las maquiladoras deben regresar a su país los residuos o tóxicos de sus procesos industriales. También es sabido que las autoridades mexicanas no han estado en condiciones de vigilar el cumplimiento de tal disposición. Así, es altamente improbable que las maquiladoras, en el pasado reciente, hayan regresado voluntariamente sus residuos peligrosos al norte de la frontera. Muy probablemente, desde entonces, la frontera empezó a convertirse en basurero de las maquiladoras "sucias". 18

\footnotetext{
${ }^{18}$ En fecha reciente, el subsecretario de ecología de la antigua sEDUE señaló que el $50 \%$ de las maquiladoras fronterizas genera desechos peligrosos.
} 
Habrá que añadir, que en los últimos años, la frontera mexicana empezó a recibir residuos tóxicos provenientes de Estados Unidos que no encontraban donde ser depositados en aquel país. Parece haber contribuido a ello el desmantelamiento del aparato proteccionista mexicano, es decir, la progresiva apertura del mercado mexicano a los productores extranjeros, principalmente estadounidenses, y la ignorancia y corrupción locales. ${ }^{19}$ Hay elementos para suponer que en los últimos afios, algunos funcionarios aduanales han permitido la entrada ilegal a México de residuos o sustancias tóxicas o peligrosas (STPS). ${ }^{20}$

Aparentemente, la permanencia y el flujo ilegales de STPS no generó conflictos o demandas que no pudieran ser controladas políticamente. A mediados de los años ochenta, todos parecían conformes: los maquiladores; cl gobierno mexicano, que veía multiplicarse las plantas maquiladoras; los importadores a México de residuos peligrosos; y quizá también la población mexicana, ignorante del proceso. Pero a mediados de la década surgieron algunas voces del lado estadounidense de la frontera. De nada servía a los productores sandieguinos — decían- huir a México y dejar allá residuos prohibidos. La naturaleza los devolvía en el agua de ríos contaminados o a través del aire. ${ }^{21}$

La segunda mitad de los años ochenta vio surgir grupos ambientalistas mexicanos a lo largo de la frontera. El efecto demostración de la sociedad civil estadounidense había encontrado terreno fértil en la sociedad mexicana, tradicionalmente sobreprotegida por $\mathrm{el}$ aparato de gobierno. Pronto la población urbana fronteriza colocó a la industria maquiladora en el banquillo de los acusados.

La cuestión es ciertamente compleja. En términos abstractos puede discutirse acerca del conflicto entre industria y desarrollo o de la viabilidad del sustainable development. Hoy algunos especialistas

\footnotetext{
19 En nuestra opinión, la sustitución de permisos previos por aranceles, la apertura comercial, habría reducido drásticamente la "renta de posición" que el sistema mexicano les permitió cobrar desde tiempo inmemorial a sus funcionarios aduanales y que éstos hacían efectiva a casi todo viajero intemacional. En la búsqueda de fuentes de ingreso sustitutas, la importación jegal de sustancias tóxicas y peligrosas pudo haberse vuelto rentable.

${ }^{20} \mathrm{La}$ importación, si no ilegal cuando menos consentida, de sustancias tóxicas a México encuentra antecedentes en 1977, cuando organizaciones civiles estadounidenses denunciaron el uso del paraquat en la campaña contra las drogas en México. Un año después, los tomateros de La Florida, con intenciones extraecologistas, denunciaron el uso de plaguicidas prohibidos en E.U. en exponaciones agrícolas mexicanas a los E.U. En 1984 fue público el uso descuidado del galecrom (sustancia de uso restringido en E.U.) en nuestro país. El traslado deliberado de desechos tóxicos a México fue público en 1981, cuando 260 tambores con this fueron descubiertos en Zacatecas. El programa ambiental frontenzo (1992) apunta algunas acciones conjuntas ejercidas para contener este proceso.

21 Reficjo de este proceso es el trabajo de Joseph Nalven (1984).
} 
proponen procedimientos o códigos de conducta a los industriales maquiladores (McIntosh, 1992). Otros más, clasifican ya a la maquila según su actitud frente a la comunidad y el medio ambiente (Stoddard, 1991). El asunto de los desechos tóxicos o peligrosos en la frontera, asunto en el que ciertamente la IM tiene mucho que decir, se ha convertido en un punto a tratar en las negociaciones bilaterales.

\section{ALGUNAS PERSPECTIVAS DE LA IM FRONTERIZA}

\section{Crecimiento}

Los analistas del sector apuntaron siempre que las altas tasas de crecimiento de la ocupación maquiladora no podrían mantenerse indefinidamente. Anunciaban en los años setenta, por ejemplo, el agotamiento local de la mano de obra femenina; cuando éste fue el caso, en Nogales, por ejemplo, las maquiladoras no tuvieron problema en sustituirla con fuerza de trabajo masculina. La falta de infraestructura local tampoco fue obstáculo para el crecimiento del sector; en alguna localidad donde los teléfonos locales eran casi inservibles, los maquiladores instalaron su propio servicio de comunicación que pronto fue absorbido por las alarmadas autoridades mexicanas (la llegada de los teléfonos celulares resolvió el problema).

Al margen de buenos o malos augurios, lo cierto es que la ocupación maquiladora siguió duplicándose cada cinco años. ${ }^{22}$ Pero también es real que el último año 1991 mostró claros signos de desaceleración. ${ }^{23}$ Cabe, por lo tanto, una mínima reflexión acerca de los probables escenarios que encontrará la maquiladora en los años por venir.

\section{La integración y la IM}

Entre los factores externos que pudieran alentar el desarrollo de la industria maquiladora en nuestro país en los años que vienen, se

\footnotetext{
22 Como se apuntó arriba, a ellopudo haber contribuido que, a mediados de la década, muchas plantas industriales en crisis pudieron acogerse al régimen maquilador, lo que habría inflado la cifra de las maquiladoras en el interior del país.

Ya en enero de 1991 se anunciaban despidos en Matamoros: en febrero, la cancelación de proyectos en Tijuana; en marzo, el cierre de maquiladoras en Reynosa y el trabajo a medio gas en Nuevo Laredo. Sin intentar explicar los hechos, INECI reportó una contracción significativa de la IM, de diciembre de 1990 a enero de 1991 (La Jornada, 3 de julio de 1991). Finalmente, en fecha reciente, la CANACINTRA apuntó que 1991 habia sido un mal año para el sector, y que la ocupación y el número de plantas se había reducido en 6.5 y $10 \%$, respectivamente (La Jornada, 8 de marzo de 1992).
} 
pueden contar: la regionalización ${ }^{24}$ real de la economía mundial y el no menos real alineamiento económico y político mexicano con el bloque estadounidense, o la región norteamericana. Los promotores de la integración, tanto mexicanos como estadounidenses, industriales o académicos, son también promotores de la maquila, más genéricamente, del comercio intrafirma, indicador de la progresiva integración. ${ }^{25}$ Los más enterados aceptan las deficiencias de la maquila, pero le atribuyen un carácter pasajero. $^{26}$

Comose señalóantes, la liberalizaciónmexicana, entreotros muchos efectos, disuelve ya el régimen excepcional del que han gozado las maquiladoras al hacerlo extensivo a toda inversión extranjera directa (IFD). Tal disolución se aceleraría con el Tratado de Libre Comercio de América del Norte.

Al margen de sus efectos interiorizadores sobre la maquila, la apertura del interior mexicano a la IED puede tener un efecto paralelo que habrá que evitar. Será entonces quizá más atractivo para las industrias sucias no registrarse como maquiladores y no verse obligadas a reexportar sus residuos tóxicos o peligrosos. La década de los noventa bien podría señalar la explosión de la inversión extranjera directa, pero "sucia", cada vez más interiorizada y fuera del régimen maquilador. Por tanto, sus residuos serían considerados nacionales según la ley actual, y podrían legalmente ser confinados en México.

\section{Algunos obstáculos a la IM}

Nadie puede subestimar la importancia económica de la inercia integracionista ni la importancia política del alineamiento mexicano; no obstante, también hay sectores mexicanos y estadounidenses que encuẹntran excesivo, $o$ inadecuado, $o$ indeseable tal alineamiento.

La critica más acerba a la relocalización industrial estadounidense proviene de sus sindicatos que se oponen a la exportación de puestos de trabajo a otros paises. Su oposición se agudiza frente al proyectado TLC de América del Norte. Argumentan que las condiciones sociopolíticas mexicanas, que hacen posible el trabajo infantil y en general los bajísimos estándares laborales, hacen de México un socio sólo deseable por cierta industria explotadora. A los ojos de algunos estadounidenses esta huida es inaceptable.

\footnotetext{
24 Es casi evidente que, aunque se hable de un proceso de globalización o intemacionalización de la economia, lo que parece estarse conformando son bloques supranacionales, definidos por regiones geográficas: Europa, el Sudeste Asiático, América del Norte.

25 Véasc, por ejemplo, Sidney Weintraub (1990).

26 Por ejemplo, Sidney Weintraub (1991).
} 
Esta crítica se suma a la de los ambientalistas de ambas naciones, quienes señalan que las maquiladoras, y en general cierta industria "sucia" estadounidense, emigra a otros países, como México, en busca de regulaciones ambientales menos estrictas y de autoridades permisivas. A los ojos de una minoría esta huida también es inaceptable, sobre todo cuando llega tan sólo al otro lado de la línea fronteriza.

En suma, la oposición interna estadounidense a la maquiladora fronteriza es creciente, y ello no puede ignorarse en un año electoral y en medio de la recesión económica vecina que parece ya haber anunciado sus efectos en nuestra frontera en 1991. Tampoco puede subestimarla el gobiemo mexicano interesado en finiquitar un acuerdo comercial internacional trabajosamente negociado. La inercia maquiladora fronteriza, importante como es, será inevitablemente afectada por nuevas fuerzas, algunas de las cuales creemos vislumbrar aquí.

\section{CUADRO 2. México, entidades, municipios y zonas fronterizas del norte. Población según el tamaño de la localidad en que habita 1970-1990 (por cientos).}

\begin{tabular}{|c|c|c|c|c|c|c|c|c|c|c|c|c|}
\hline \multirow[b]{2}{*}{ México } & \multicolumn{3}{|c|}{$\begin{array}{l}\text { Población en } \\
\text { localidades } \\
\text { menores de } \\
5000 \text { hab. }\end{array}$} & \multicolumn{3}{|c|}{$\begin{array}{l}\text { Población en } \\
\text { localidades } \\
\text { de entre } \\
5 \text { y } 10000 \text { hab. }\end{array}$} & \multicolumn{3}{|c|}{$\begin{array}{c}\begin{array}{c}\text { Población en } \\
\text { localidades } \\
\text { de entre }\end{array} \\
10 \text { y } 20000 \text { hab. } \\
197019801990\end{array}$} & \multicolumn{3}{|c|}{$\begin{array}{l}\text { Población en } \\
\text { localidades } \\
\text { mayores de } \\
20000 \text { hab. }\end{array}$} \\
\hline & 49.9 & 9.8 & 34.4 & 7.8 & 5.3 & 5.2 & 7.1 & 5.1 & 4.9 & 35.3 & 49.8 & 55.4 \\
\hline BPNM & 33.1 & 25.1 & 18.2 & 4.1 & 3.6 & 3.1 & 4.6 & 3.1 & 2.9 & 58.2 & 68.1 & 75.6 \\
\hline MFNM & & 15.9 & 10.9 & & 3.4 & 2.5 & & 3.1 & 2.1 & & 77.6 & 84.4 \\
\hline FNM & 14.9 & 12.1 & 8.1 & 0.9 & 2.4 & 2.1 & 0.7 & 0.5 & 0.5 & 83.6 & 84.9 & 89.2 \\
\hline
\end{tabular}

FUENTE: Sistema Geomunicipal 90.

EFNM. Entidades fronterizas del norte de México (Baja California, Sonora. Chihuahua, Coahuila, Nuevo León y Tamaulipas).

MFNM. Municipios fronterizos del norte de México. Conjunto de las 36 municipalidades fronterizas del norte de México.

ZFNM. Zonas fronterizas del norte de México. Conjunto de las catorce principales municipalidades urbanas del norte de México: Mexicali, Tecate, Tijuana, San L. Río Colorado, Nogales, Agua Prieta, Juárez, Acuña, Piedras Negras, Nuevo Laredo, Reynosa, Río Bravo, Matamoros y Ensenada. 
CUADRO 3. México. Población de las principales ciudades del extremo norte. 1900 a 1990 (aquellas mayores de 15,000 habitantes en 1970).

\begin{tabular}{|c|c|c|c|c|c|c|c|c|c|c|}
\hline & 1900 & 1910 & 1921 & 1930 & 1940 & 1950 & 1960 & 1970 & 1980 & 1990 \\
\hline Tijuana & 242 & 733 & 1028 & 8384 & 16486 & 59952 & 152473 & 341067 & 429500 & 698752 \\
\hline Tecate & & & & & & & & & 23909 & 40240 \\
\hline Ensenada & 1726 & 2170 & 2178 & 3042 & 4616 & 18150 & 42561 & 79146 & 120483 & 169426 \\
\hline Mexicali & & 462 & 6782 & 14842 & 18775 & 65749 & 179539 & 276167 & 341559 & 438377 \\
\hline San Luis R.C. & & & 175 & 910 & 558 & 4079 & 28545 & 51118 & 76684 & 95461 \\
\hline Caborca & 915 & 1190 & 1404 & 1880 & 2321 & 3997 & 9338 & 21308 & & \\
\hline Nogales & 2738 & 3177 & 13475 & 14061 & 13886 & 24478 & 37657 & 53119 & 65603 & 105873 \\
\hline Cananea & 891 & 8909 & 6974 & 12932 & 11006 & 17892 & 19683 & 17085 & & \\
\hline $\mathrm{Naco}$ & & & & & & & & & 3742 & 4035 \\
\hline Agua Prieta & & 656 & 3236 & 4674 & 4106 & 10471 & 15339 & 21017 & 28362 & 37664 \\
\hline Casas Grandes & 2187 & 7708 & 1827 & 1510 & 1126 & 1102 & 11687 & 20345 & & \\
\hline Las Palomas ${ }^{a}$ & & & & & & & & & $2072^{b}$ & 3707 \\
\hline Ciudad Juárez. & 8218 & 10621 & 19457 & 39669 & 48881 & 122566 & 262119 & 414908 & 544496 & 789522 \\
\hline Ojinaga & & & & & & & & & 18162 & 18177 \\
\hline Ciudad Acuña & 667 & 933 & 2423 & 5350 & 5607 & 11372 & 20048 & 30838 & 38898 & 52983 \\
\hline Piedras Negras & 7888 & 8518 & 14233 & 15878 & 15663 & 27581 & 44992 & 40885 & 67455 & 96178 \\
\hline Nueva Rosita & & & 6151 & 10418 & 25551 & 29625 & 34302 & 34713 & & \\
\hline Sabinas & 939 & 2570 & 3086 & 4541 & 6825 & 11249 & 16076 & 20780 & & \\
\hline Sabinas Hidalgo & 4089 & 5173 & 4762 & 5828 & 6912 & 8631 & 11592 & 17660 & & \\
\hline
\end{tabular}




\section{Continuación cuadro 3.}

\begin{tabular}{|c|c|c|c|c|c|c|c|c|c|c|}
\hline Nuevo Laredo & 6548 & 8143 & 14998 & 21636 & 28872 & 57668 & 92627 & 152325 & 201731 & 218413 \\
\hline Reynosa & 1975 & 1475 & 2107 & 4840 & 9412 & 34087 & 74140 & 140480 & $249929^{c}$ & $332755^{c}$ \\
\hline Río Bravo & & & 525 & 746 & 936 & 4610 & 17500 & 39993 & & \\
\hline Valle Hermoso & & & & & 87 & 7025 & 15769 & 19412 & & \\
\hline Matamoros & 8347 & 7390 & 9215 & 9733 & 15699 & 45846 & 92327 & 14060 & 188745 & 266055 \\
\hline Pobl. fronteriza & 47370 & 69828 & 114036 & 180874 & 237325 & 566130 & 1178314 & 1806426 & 2401330 & 3367618 \\
\hline Pob. edos. front. & & & & & & & & & & $\begin{array}{r}13221 \\
0.255\end{array}$ \\
\hline Pob. Méx. (Miles) & 13607 & 15160 & 14335 & 16553 & 19654 & 25791 & 34923 & 48225 & 66847 & 81141 \\
\hline & 0.003 & 0.005 & 0.008 & 0.011 & 0.012 & 0.022 & 0.034 & 0.037 & 0.036 & 0.042 \\
\hline
\end{tabular}

FUENTE: 1900 a 1970: Luis Unikel et al., El desarrollo urbano de México: Diagnóstico e implicaciones futuras, El Colegio de México, 1976; 1980 y 1990: X y XI Censos de Población y Vivienda, INEGI-SPP.

NOTAS: ${ }^{\text {a }}$ Actualmente se llama Gral. Rodrigo M. Quevedo.

${ }^{\mathrm{b}}$ Estimación.

${ }^{\mathrm{c}}$ Incluye Río Bravo, Tamaulipas. 
CUADRO 4. Zona fronteriza mexicana. Plantas maquiladoras por localidad.

\begin{tabular}{lrrrrrrrrrrrrr}
\hline & 1979 & 1980 & 1981 & 1982 & 1983 & 1984 & 1985 & 1986 & 1987 & 1988 & 1989 & 1990 & 1991 \\
\hline Tijuana & 101 & 123 & 127 & 124 & 131 & 147 & 192 & 238 & 296 & 355 & 436 & 469 & 473 \\
Ciudad Juárez & 103 & 121 & 128 & 120 & 135 & 155 & 168 & 100 & 199 & 240 & 232 & 275 & 239 \\
Mexicali & 77 & 79 & 64 & 54 & 55 & 67 & 75 & 86 & 109 & 135 & 147 & 139 & 133 \\
Matamoros & 46 & 50 & 46 & 41 & 40 & 39 & 35 & 43 & 60 & 72 & 88 & 94 & 94 \\
Tecate & 20 & 22 & 20 & 17 & 19 & 25 & 31 & 33 & 42 & 57 & 71 & & \\
Nogales & 47 & 59 & 58 & 54 & 47 & 46 & 49 & 51 & 54 & 61 & 68 & 61 & 86 \\
Reynosa & 13 & 17 & 17 & 17 & 19 & 22 & 27 & 29 & 34 & 43 & 60 & & \\
Nuevo Laredo & 15 & 14 & 12 & 12 & 12 & 14 & 15 & 23 & 33 & 44 & 56 & & \\
Piedras Negras & 16 & 18 & 16 & 17 & 17 & 17 & 18 & 21 & 24 & 32 & 39 & & \\
Ciudad Acuña & 10 & 13 & 15 & 16 & 16 & 22 & 24 & 26 & 31 & 35 & 36 & & \\
Ensenada & 5 & 6 & 4 & 5 & 6 & 9 & 9 & 9 & 11 & 22 & 32 & & \\
Agua Prieta & 21 & 22 & 19 & 20 & 24 & 27 & 24 & 26 & 26 & 27 & 27 & & \\
Otras localidades & 62 & 71 & 75 & 75 & 73 & 76 & 89 & 119 & 194 & 250 & 326 & & \\
& 536 & 544 & 526 & 506 & 523 & 590 & 667 & 765 & 919 & 1131 & 1314 & 1038 & 1025 \\
Total nacional & 540 & 620 & 605 & 585 & 800 & 672 & 760 & 890 & 1125 & 1396 & 1655 & 1920 & 1959 \\
& & & & & & & & & & & & & \\
\hline
\end{tabular}

FUENTE: INEGI 
CUADRO 5. Zona fronteriza mexicana. Ocupación en el sector maquilador por localidad.

\begin{tabular}{|c|c|c|c|c|c|c|c|c|c|c|c|c|c|}
\hline & \multicolumn{13}{|c|}{ Personal ocupado promedio (en miles) } \\
\hline & 1979 & 1980 & 1981 & 1982 & 1983 & 1984 & 1985 & 1986 & 1987 & 1988 & 1989 & 1990 & 1991 \\
\hline Ciudad Juárez & 36 & 39 & 44 & 43 & 54 & 72 & 76 & 87 & 96 & 111 & 124 & 128 & 128 \\
\hline Tijuana & 11 & 12 & 14 & 15 & 17 & 23 & 26 & 30 & 39 & 50 & 58 & 57 & 64 \\
\hline Matamoros & 16 & 15 & 15 & 15 & 16 & 19 & 21 & 23 & 27 & 32 & 38 & 37 & 38 \\
\hline Nogales & 12 & 13 & 13 & 12 & 13 & 16 & 15 & 15 & 19 & 28 & 23 & 18 & 19 \\
\hline Reynosa & 4 & 5 & 6 & 9 & 11 & 14 & 18 & 16 & 17 & 20 & 23 & & \\
\hline Mexicali & 6 & 7 & 8 & 6 & 7 & 10 & 11 & 13 & 16 & 20 & 21 & 22 & 21 \\
\hline Nuevo Laredo & 2 & 2 & 3 & 3 & 3 & 4 & 4 & 4 & 7 & 11 & 15 & & \\
\hline Ciudad Acuña & 3 & 3 & 3 & 3 & 5 & 5 & 6 & 8 & 10 & 11 & 13 & & \\
\hline Piedras Negras & 3 & 3 & 2 & 2 & 3 & 4 & 4 & 5 & 6 & 7 & 8 & & \\
\hline Agua Prieta & 4 & 5 & 4 & 3 & 4 & 6 & 6 & 6 & 6 & 6 & 7 & & \\
\hline Tecate & 1 & 1 & 1 & 1 & 1 & 2 & 2 & 2 & 4 & 4 & 5 & & \\
\hline Ensenada & & & & & & & & 1 & 1 & 1 & 2 & & \\
\hline Otras localidades & 11 & 13 & 15 & 14 & 17 & 24 & 27 & 39 & 56 & 72 & 91 & & \\
\hline Total nacional & 111 & 119 & 131 & 127 & 151 & 200 & 212 & 250 & 305 & 370 & 430 & 446 & 489 \\
\hline
\end{tabular}

FUENTE: INEGI 
CUADRO 6. Zona fronteriza mexicana. Industria maquiladora. Número de plantas y empleados por localidad, 1988-1991.

\begin{tabular}{|c|c|c|c|c|c|c|c|c|}
\hline & $\begin{array}{c}1988 \\
\text { Plantas }\end{array}$ & $\begin{array}{c}1988 \\
\text { Ocupación } \\
\text { (miles) }\end{array}$ & $\begin{array}{c}1989 \\
\text { Plantas }\end{array}$ & $\begin{array}{c}1989 \\
\text { Ocupación } \\
\text { (miles) }\end{array}$ & $\begin{array}{c}1990 \\
\text { Plantas }\end{array}$ & $\begin{array}{c}1990 \\
\text { Ocupación } \\
\text { (miles) }\end{array}$ & $\begin{array}{c}1991 \\
\text { Plantas }\end{array}$ & $\begin{array}{c}1991 \\
\text { Ocupación } \\
\text { (miles) }\end{array}$ \\
\hline Ciudad Juárez & 248 & 111 & 252 & 124 & 275 & 123 & 259 & 128 \\
\hline Tijuana & 355 & 60 & 436 & 58 & 469 & 57 & 478 & 64 \\
\hline Matamoros & 72 & 32 & 88 & 38 & 94 & 37 & 94 & 38 \\
\hline Nogales & 61 & 23 & 68 & 23 & 61 & 18 & 55 & 19 \\
\hline Reynosa & 43 & 20 & 60 & 23 & & & & \\
\hline Mexicali & 135 & 20 & 147 & 21 & 139 & 22 & 133 & 21 \\
\hline Nuevo Laredo & 44 & 11 & 56 & 15 & & & & \\
\hline Ciudad Acuña & 35 & 11 & 38 & 13 & & & & \\
\hline Piedras Negras & 32 & 7 & 39 & 8 & & & & \\
\hline Agua Prieta & 27 & 6 & 27 & 7 & & & & \\
\hline Tecate & 57 & 4 & 71 & 5 & & & & \\
\hline Ensenada & 22 & 1 & 32 & 2 & & & & \\
\hline \multirow[t]{2}{*}{ Otras localidades } & 250 & 72 & 326 & 91 & & & & \\
\hline & 1131 & & 1314 & & 1038 & & 1025 & \\
\hline Total Nacional & 1396 & 370 & 1655 & 430 & 1920 & 446 & 1959 & 489 \\
\hline
\end{tabular}

FUENTE: INEGI 
CUADRO 7. Personal ocupado en la industria maquiladora de exportación, por rama de actividad económica. 1981- 1989.

\begin{tabular}{|c|c|c|c|c|c|c|c|c|c|c|c|c|c|c|c|}
\hline & Total & $\begin{array}{l}\text { Municipios } \\
\text { fronterizos }\end{array}$ & $\mathrm{ME} / \mathrm{E}$ & Trans. & $\mathrm{EE} / \mathrm{E}$ & Otman & Mueb. & Cost. & Serv & $\mathrm{J} / \mathrm{D}$ & Calz & Herr & Alim. & Quim. & $\begin{array}{l}\text { Municip } \\
\text { No front. }\end{array}$ \\
\hline 1981 & 130973 & 116450 & 36935 & 10108 & 31801 & 7451 & 3236 & 14273 & 5105 & 2666 & 1821 & 1402 & 1572 & 80 & 14523 \\
\hline 1982 & 127048 & 113227 & 35641 & 11537 & 30787 & 6948 & 3032 & 11891 & 5838 & 2565 & 2048 & 1327 & 1818 & n. & 13821 \\
\hline 1983 & 150867 & 134915 & 40002 & 18814 & 33255 & 7451 & 4752 & 12885 & 8088 & 3477 & 2779 & 1514 & 1898 & n. & 15952 \\
\hline 1984 & 199684 & 178909 & 53316 & 28040 & 41691 & 9655 & 6201 & 15161 & 9118 & 8172 & 9848 & 2154 & 1753 & n. & 22775 \\
\hline 1985 & 211968 & 186000 & 48943 & 36978 & 38994 & 12473 & 6522 & 15089 & 11187 & 7285 & 4328 & 2386 & 1855 & n. & 25968 \\
\hline 1986 & 249833 & 212291 & 53878 & 43055 & 42617 & 16291 & 9632 & 9632 & 18048 & 7110 & 4999 & 3253 & 2185 & n. & 37542 \\
\hline 1987 & 305253 & 251403 & 66669 & 51326 & 43093 & 21637 & 14349 & 19399 & 13718 & 9470 & 4942 & 3787 & 2464 & 547 & 53850 \\
\hline 1988 & 369489 & 298863 & 79888 & 64213 & 47769 & 28771 & 17770 & 20289 & 13672 & 11443 & 5786 & 4878 & 3442 & 1165 & 70626 \\
\hline 1989 & 429725 & 339918 & 87079 & 75765 & 53463 & 34495 & 21384 & 20672 & 15269 & 12154 & 7298 & 5696 & 4361 & 2282 & 89807 \\
\hline
\end{tabular}




\section{Cuadro 7. Continuación (porcentajes).}

\begin{tabular}{|c|c|c|c|c|c|c|c|c|c|c|c|c|c|c|c|}
\hline & Total & $\begin{array}{l}\text { Municipios } \\
\text { fronterizos }\end{array}$ & $\mathrm{ME} / \mathrm{E}$ & TRANS & EE/E & Otman & Mueb. & Cost. & Serv & $J / D$ & Calz & Herr & Alim. & Quím. & $\begin{array}{l}\text { Municip. } \\
\text { no front. }\end{array}$ \\
\hline 1981 & 100.0 & 88.9 & 28.2 & 7.7 & 24.3 & 5.7 & 2.5 & 10.9 & 3.9 & 2.0 & 1.4 & 1.1 & 1.2 & 0.1 & 11.1 \\
\hline 1982 & 100.0 & 89.1 & 28.1 & $\cdot 9.1$ & 24.2 & 5.5 & 2.4 & 9.4 & 4.6 & 2.0 & 1.6 & 1.0 & 1.3 & 0.0 & 10.9 \\
\hline 1983 & 100.0 & 89.4 & 26.5 & 12.5 & 22.0 & 4.9 & 3.1 & 8.5 & 5.4 & 2.3 & 1.8 & 1.0 & 1.3 & 0.0 & 10.6 \\
\hline 1984 & 100.0 & 88.6 & 26.7 & 14.0 & 20.9 & 4.8 & 3.1 & 7.6 & 4.6 & 3.1 & 1.8 & 1.1 & 0.9 & 0.0 & 11.4 \\
\hline 1985 & 100.0 & 87.7 & 23.1 & 17.4 & 18.4 & 5.9 & 3.1 & 7.1 & 5.3 & 3.4 & 2.0 & 1.1 & 0.9 & 0.0 & 12.3 \\
\hline 1986 & 100.0 & 85.0 & 21.6 & 17.2 & 17.1 & 6.5 & 3.9 & 3.9 & 5.2 & 2.8 & 1.7 & 1.3 & 0.9 & 0.0 & 15.0 \\
\hline 1987 & 100.0 & 82.4 & 21.8 & 16.8 & 14.1 & 7.1 & 4.7 & 6.4 & 4.5 & 3.1 & 1.6 & 1.2 & 0.8 & 0.2 & 17.6 \\
\hline 1988 & 100.0 & 80.9 & 21.6 & 17.4 & 12.9 & 7.8 & 4.8 & 5.5 & 3.7 & 3.1 & 1.6 & 1.3 & 0.9 & 0.3 & 19.1 \\
\hline 1989 & 100.0 & 79.1 & 20.3 & 17.6 & 12.4 & 8.0 & $5: 0$ & 4.8 & 3.6 & 2.8 & 1.7 & 1.3 & 1.0 & 0.5 & 20.9 \\
\hline
\end{tabular}

FUENTE: INEGI

NOTAS: ME/E Materiales y accesorios eléctricos y electrónicos.

TRANS Construcción, reconstrucción y ensamble de equipo de transporte y accesorios.

$\mathrm{EE} / \mathrm{E}$ Ensamble de maquinaria, equipo, aparatos y artículos eléctricos y electrónicos.

OTMAN Otras industrias manufactureras.

MUEB Ensamble de muebles, sus accesorios y otros productos de madera y metal.

cost Ensamble de prendas de vestir y otros productos confeccionados con textiles.

SERV Servicios.

J/D Ensamble de juguetes y artículos deportivos.

CALZ Fabricación de calzado e industria del cuero.

HERR Ensamble y reparación de herramientas, equipo y sus partes, excepto eléctrico.

ALuM Selección, preparación, empaque y enlatado de alimentos.

QUIM Productos químicos 


\section{BIBLIOGRAFÍA}

CASTILLO, Víctor y R. de Jesús Ramírez A. 1992. "La subcontratación en la industria maquiladora de Asia y México", Comercio Exterior, Vol. 42, no.1, enero, México.

CENTRO DE INVESTIGACION Y DOCENCIA ECONOMICA. 1983. Zonas fronterizas (México-Estados Unidos). México.

FERNÁNDEZ, Jose Luis y Jesús Tamayo. 1986. "Industry on the Northern Border of Mexico", Industrial Strategy and Planning in Mexico and the United States. Westview Press, (Westview Special Studies in International Economics and Business).

GUAJARDO, Ramón G. 1992. "Efectos de las maquiladoras en el producto, el ingreso y el empleo en México". Comercio exterior. Vol. 42, no. 1 México.

HYUN Sook Lee Kim. 1992. "Diversidad de los procesos de crecimiento económico de los cuatro tigres asiáticos", Comercio Exterior. Vol. 42, no. 2, México, febrero.

McINTOSH, Molly. 1992. Doing Business in Mexico: The Evolving Legal Framework (Enviroment Considerations Regarding Waste Disposal, International Transboundary Resources Center. The University of New Mexico, Albuquerque, N.M., enero 1992.

NALVEN, Joseph. 1984. "Prophets of Boom, Prophets of Doom: The Future of Border Industrial Development in the San Diego-Tijuana Region", Journal of Chicano Studies. Invierno/verano de 1984, Vol. II, nos. 1-2.

QUINTANILLA, Ernesto. 1991. "Tendencias recientes de la localización en la industria maquiladora". Comercio exterior, vol. 41, no. 9, México, septiembre.

STODDARD, Ellwin. 1991. "The Good, the Bad and the Ugly", Journal of Borderland Studies, invierno.

WEINTRAUB, Sidney. 1990. A Marriage of Convenience. Relations Between Mexico and the United States. Oxford University Press.

- 1991. "The Maquiladora Industry in Mexico: Its Transitional Role". En: Díaz-Briquets y Weintraub (eds.). Regional and Sectoral Development in Mexico as Alternatives to Migration. West-View Press.

\section{Periódicos:}

LA JORNADA. 1992. "Se ajustará el decreto de la industria maquiladora", 16 de octubre de 1992. 